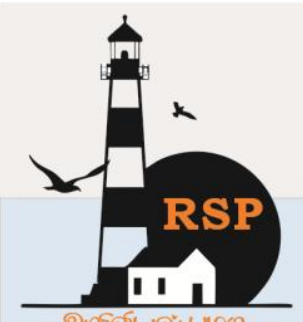

INTERNATIONAL RESEARCH JOURNAL ON ADVANCED SCIENCE HUB Open Access
Open $2582-4376$

RSP SCIENCE HUB

(The Hub of Research Ideas)

Available online at www.rspsciencehub.com

\title{
Melioration of the Supply Chain Performance in the Warehouse Management System by Implementing the Fvi-6-Sigma Technique with Beacon Technology
}

Natesan Andiyappillai ${ }^{1}$, Dr.P.Arivalagan ${ }^{2}$, Dr.T.Prakash ${ }^{3}$.

${ }^{1}$ WMS Solution Expert, CEVA Logistics US Inc, 15350 Vickery Dr, Houston, TX 77032, US.

${ }^{2}$ Associate Professor, Department of Mechanical Engineering, Info Institute of Engineering, Coimbatore, Tamil Nadu, India.

${ }^{3}$ Professor, Department of Mechanical Engineering, SNS College of Technology, Coimbatore, Tamil Nadu, India.

natesan.andiyappillai@gmail.com ${ }^{1}$

\section{Abstract}

Supply chain is becoming more critical and challenging than ever before due to challenging market conditions and ever-changing dynamic customer requirements. Though there are numerous ways and techniques of improving the supply chain performance, there are very few attempts being made in the context of Warehouse Management System (WMS) implementations. Hence, this research is attempted to help the supply chain industry to exhibit the Forward Vertical Integration (FVI) technique and 6-Sigma method for the effective supply chain improvement along with Beacon Technology. Forward vertical integration (FVI) is a business approach that involves business activities which include the method of the direct circulation or supply of an enterprise inventory. And, being Beacon technology is one of the leading tracker technologies that offer different functional capabilities such as power source, frequency, read range, data storage capacity and others, it has immediate benefits over the traditional barcodes. Hence, this research paper is going to investigate and publish the results when the beacon technology is integrated with the FVI-6-Sigma technique for the effective improvement of the supply chain, with the primary focus on WMS. It is evident based on the research conducted on a supply chain organization that the Beacon technology when integrated with the FVI-6-Sigma technique helps improve the performance of the supply chain, especially on the context of Warehouse Management System implementations.

Keywords: Supply Chain Management, Warehouse Management System, Forward Vertical Integration, 6-Sigma and Beacon technology.

\section{Introduction}

Supply Chain Management is all about managing the supply chain end to end from Suppliers thru the final consumers. And, this can be of gettingthe manufactured products or services to the customer or user. A typical supply chain involves activities such as sourcing materials from suppliers, transporting the raw materials to the manufacturing plant, transforming the raw materials into finished products, transporting those finished products to the distribution centers, and finally distributing them to the end user. And, the different partners / stakeholders involved in the supply chain are; vendors / suppliers, producers / manufacturers, warehouses / distributions, transportation companies and retailers / showrooms. The fundamental element of a supply chain is to fulfill the market / customer demand at best possible price, timeline, and quality. 


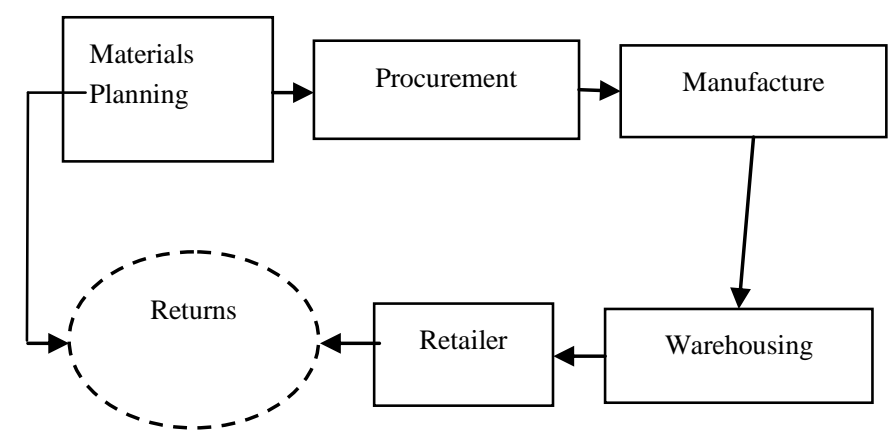

Fig:1 a Supply Management Model

Every organization is working towards keeping their supply chain lean and responsive which can directly contribute to the financial benefits. And, the performance of one partner in a supply chain greatly impacts the entire supply chain.

Warehousing and Distribution is one of the key elements in the supply chain to ensure all the partners are integrated closely and the activities within these partners are visible for better and quick decision-making capabilities based on the market demand and behavior. Warehousing is an activity that manages the storage and movement of materials effectively and efficiently.

As many could imagine, Warehousing is not simply about storing the materials in a building but also manages the processes such as Product Quality check, Testing, Value Added services and Customer Compliance etc.

There are three types of warehouses in the market and the sector that it serves can easily interpreted from their names:

o Public Facilities

o Third PartyLogistics Centers

o Self-Owned Facilities

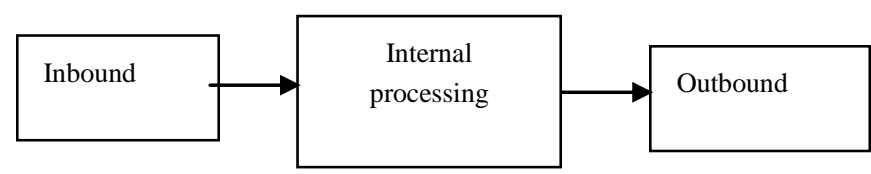

\section{Fig:2 a High-level Warehousing / Distribution Model}

It looks very simple by looking at the Figure 2 about the Warehousing model but there are many sub-activities within each activity and each of them is important and critical for the business. And, managing these activities in the system such as Warehouse Management System is critical for real-time data capture and visibility.

Impact of Improper Warehousing and Distribution As like any other field or facility, a minor error or mistake could sometimes result the facility in a high financial impact.Activities such as Improper storage, ignoring the facility rules and regulations, unavailability of Warehouse Management System etc could impose a severe threat to the facility and the business. This is applicable for both forward logistics and reverse logistics. Both the process channels bring all the supply chain partners / entities in a loop for the process integrity and scalability.

There are few key challenging disturbances in the supply chain that prevents the supply chain providers or logistics service providers in delivering the right service at right time and at right cost and every service provider is working towards in mitigating these disturbances in different ways to keep the supply chain more resilient.

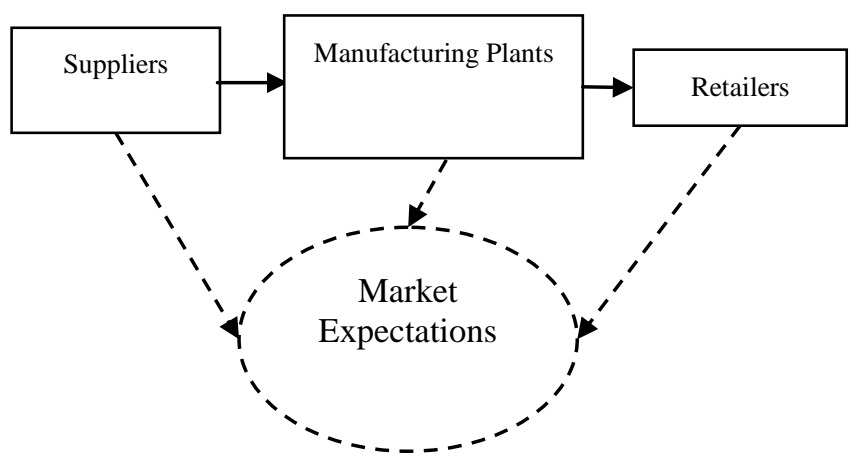

Fig:3 A Model of Supply Chain disturbances

There are both internal and external disturbances in a Supply Chain and the very challenging one is the external as to which there is no control on them as they manage the internal challenges / disturbances.

\section{Literature Study}

[1] Chakra borty et al. (2018)had detailed out on their researchthat the retailer and each of the two challenging manufacturers can be benefited by mutual product quality improvement strategies in a supply chain. On their supply chain model, two challenging manufacturers empower in the quality improvement of their produce and a familiar retailer sells those elevated quality substitutable products to the end consumers. [2] Taleizadeh et 


\section{www.rspsciencehub.com}

al. (2019) proposed about the aggressive supply chains, as long as products which can kindle the customer's demand and improve the revenues of companies is an vital objective. Therefore, three inspiring factors, together with the carbon production decline, return policy and quality step up efforts are taken into consideration in a supply chain (SC). In line with reducing carbon emission, two potential in the forward flow, including the technologies speculation and the trade and cap are working. In the reverse flow, hybrid remanufacturing of the imperfect quality products beneath knowledge allow is investigated. The impact of collecting-remanufacturing processes on carbon reduction, quality improvement, and SC performance was the key purpose of this research. [3] Aramyan et al. (2007) proposed about the performance measurement in agri-food supply chains a case study in supply chain management. [4] Ayers (2001) published a paper on the handbook of supply chain management.[5] Batson (2008) proposed a survey of best practices in automotive supplier development. [6] Beamon (1999) proposed a measuring supply chain performance. [7] Benjamin et al. (1995)had focused on electronic markets and its virtual value chains on the information superhighway and proposed the model for the performance evaluation.[8] Chopra et al. (2001) proposed a model on the supply chain management for the process evaluation and improvement. [9] Chopra et al. (2004)had extended the research and had proposed the models on Supply Chain Management. [10] Chopra et al. (2008) proposed about a Supply Chain Management for effective supply chains. [11] Chow et al (2018) proposed about a Supply Chain Management in the US and Taiwan. [12] Christopher (1994) proposed a model for more responsive on the Logistics and Supply Chain Management. [13] Christopher francis (1994) proposed about a logistics and supply chain management for an enterprise to be resilient. [14] Christy et al. (1994) proposed a method of maintaining the supply chain relationships. [15] Cohen et al. (1989) proposed about the resource deployment analysis of global manufacturing and distribution networks. [16] Cohen and Moon (2015) proposed about the impact of production scale economies, manufacturing complexity and transportation costs on supply chain facility networks. [17] Cuthbertson and Piotrowicz (2008) proposed about the Supply Chain Best Practices Identification and Categorization of Measures and Benefits. [18] Davis (1993) proposed an effective supply chain management for organizations to be more predictive on the dynamic market conditions. [19] De Toni and Tonchia S., (2001) proposed about a performance measurement system. [20] Davis (1993) proposed about an efficient supply chain management.

\section{Problem Statement}

In the last few decades or so, Supply chain is treated asone of the most critical elements in any business organization. Any entity that disturbsthe supply network, will adversely affect the whole chain in the supply network. The major causes of supply chain activities to fail are due to the lack of the understanding or knowledge on the nature of stipulation. Supply chains have become more challenging as the disruptions to the industry seems to be increasing. Hence, there is a need for the effective method for overcoming the Supply Chain challenges and issues and improve the performance of the supply chain, especially in the context of Warehouse Management in this research.

\section{Methodology}

The novel flow for the improvement of the warehousing and the supply chain in the supply chain service provider company for their supply chain improvement.

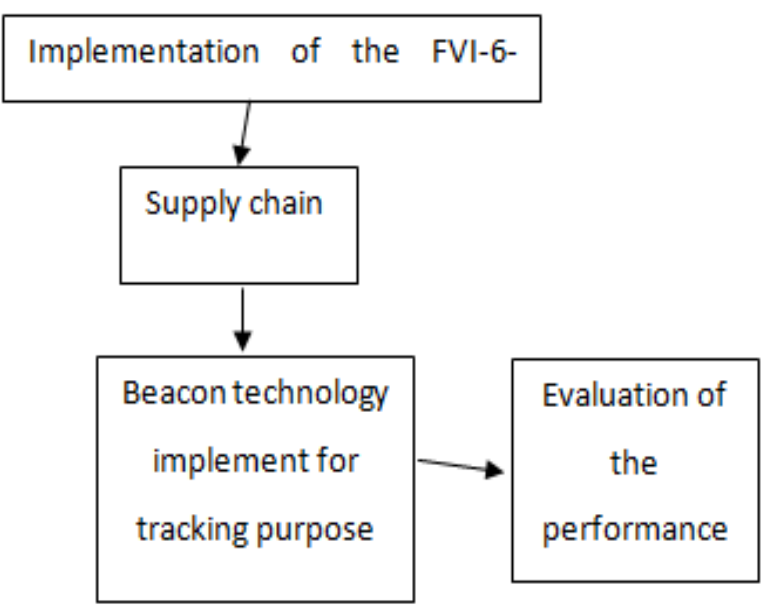

Fig:4 a Schematic representation of the proposed methodology 


\subsection{Supply Chain Process Improvement}

Whole network of entities directly or indirectly interconnected and are interdependent in serving the same consumer or else different customer. It comprises of the seller who supply raw material and producers who convert the material into products, warehouses that in which the finished goods can placed in that store, distribution centers that deliver the finished products to the retailers, and the ultimate user. Supply chains motivate the value-chains because, without them, no producer could bring out the likely products of the customers. If there is no improvement from the supply chain the producer productivity gets defected. So, for improving the supply chain a novel fusion method of FVI-6-sigma concept have to be implemented here.

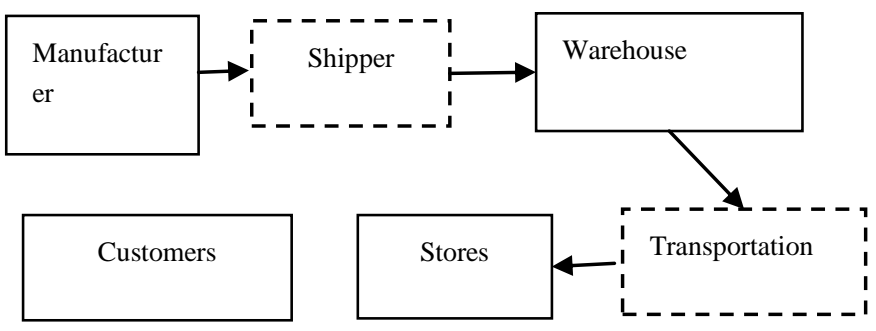

Fig:5 General process in the supply chain

\subsection{Implementing the Forward Vertical Integrationwith 6-Sigma}

The proposed integrated technique is as follows.

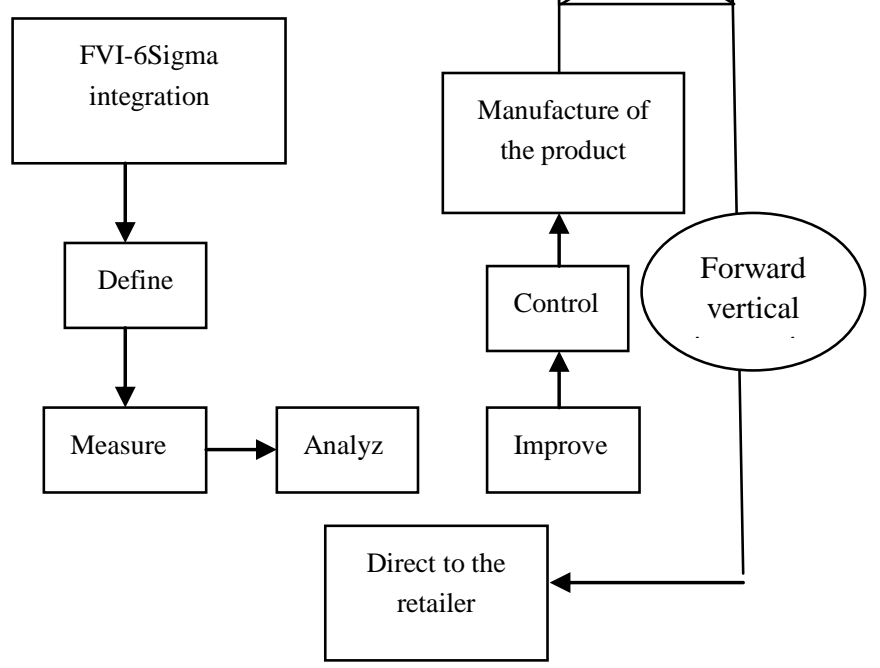

Fig:6 A proposed method Integration

\subsubsection{FVI-6Sigma integration}

FVI-6Sigma integration strategy in hand will prefer benefits for the company.The basics of the Six Sigma were essentially designed to develop the routine in the manufacturing industry, originally developed as a kind of quality control especially for the purpose of the large-scale manufacturing companies. The main purpose of this quality control system was to improve the manufacturing processes along with eliminating the number of defects found in them. Later, that the Six Sigma methodology was extended to all the other types of industries all over the world. Six Sigma is a methodology which can help the persons to improve the business methodology by using the method of the statistical analysis. It is a datadriven and extremely closely controlled methodology that ensures elimination of defects in any type of the business or any of the other organizational process. Before the process of manufacturing the product the 6-Sigma concept can gets implemented.

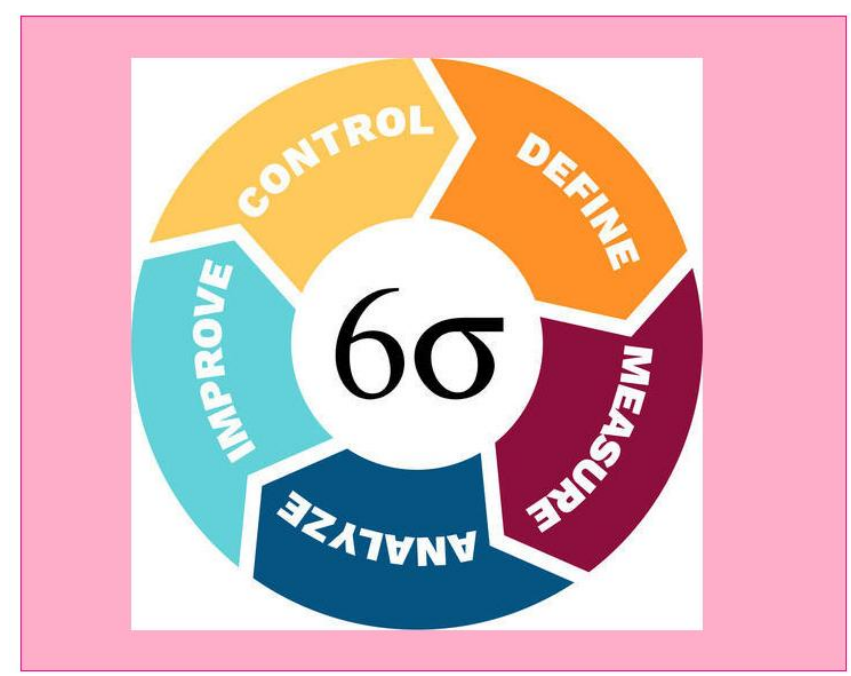

Fig:7 the Process of 6-Sigma concept

Six Sigma process that's defined by five phases:

a) Define: A survey gone out depend on the satisfied need of the customers. Then issues or the dignity of the product can be identified .Then benchmarking takes place

b) Measure - In this step, the organization can measure the performance of the existing systems and to learn what is supposed to be a baseline for all the process.

c) Analyze - This step focuses on analyzing the system to identify customs to eliminate several other defects. This can be done in a variety of 
ways, including statistical analysis to determine the root cause of an issue.

d) Improve - During this step, the research team can search for an efficient method which can serve efficient yield for the company.

e) Control - The Control step in which the company can modify instructions or product rule or method for the goal improvement it should be negligible one.

After the implementation of the 6-Sigma concept, the organization manufacturing process couldbe started because of the 6-Sigma concept we can be well prepared for the process and every process and methods are modified due to this implementation the product manufactured we be of excellent quality. For enhancing the method supply chain also be integrated.

4.2.2 Outcomes due to implementing the 6-sigma Elimination of variation and waste

After the identification of the improvement of the ideas, elimination of waste and variation in business processes will occurs. Waste is defined as anything that doesn't be useful in producing the tune-up of product or else unwanted junk for a customer.

\section{Reduced Defects}

Due to the implementation of the Six Sigma technique, employees are able to identify the problem areas very easily as well as inveterate issues that affect the overall quality and expectation of a service or product from a customer's point of view.

\section{Room for continuous improvement}

Employees who are trained by the concept of the 6-sigma concept they become more skilled and the product manufactured by them come out with an excellent quality. Hence, due to the production of the high-quality products customers are highly satisfied supply chain does not get disturbed because no one can return the product. So, theentire supply chain could also be improved.

\subsection{Implementation of the Forward Vertical Integration}

Forward vertical integration is a business concept that helps tocomplete the vertical integration of all the business stakeholders or business partners whereby business activities are extended to include control of the direct distribution or supply of products or services without any mediators or third parties. In general, this method of forward vertical integration ("taking the middleman out") is an operational strategy implemented by enterprises that wants to manage their suppliers, manufacturers and distributors directly without involving any third parties so it can increase its market or purchasing power. For a very successful forward vertical integration, an enterprise needs to maintain the business ownership greatly than other business partners on their supply chain.

The technological developments and advancement havecontributed for the forward vertical integration easy and efficient approach in the business strategy. So, the direct interconnect between the manufacturers and the retailers seems to be evident in cost savings while attaining the expected product / service quality by implementing the 6-sigma concept on this forward vertical integration technique.
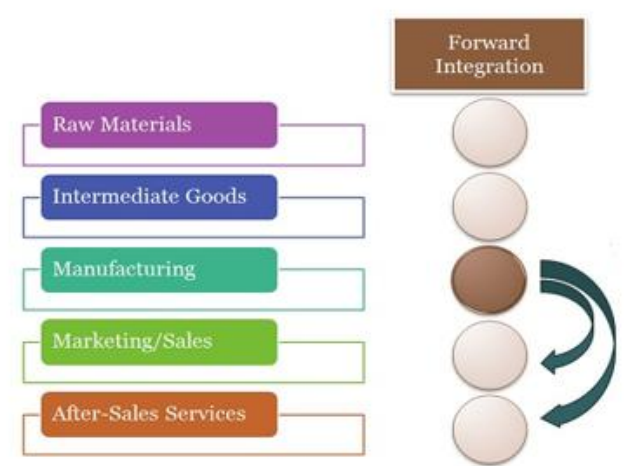

Fig:8 aMethod of forward Integration

4.3.1 Process of the integration in supply chain After the completion of the forward vertical integration within an organization, it appears that major part of the supply chain process improvementis complete, and the next step is tostreamline the supply chain integration process for the process enhancements. This is possible primarily by reducing the idleness by carefully selecting the right supply chain partners with whom the organization would want to work very closely together and make the entire logistics flow visible for every partner on the supply chain.

- Extended Enterprise: the organization or enterprise is extending the supply chain 
network to all its business partners and make them to be part of the organization or enterprise success. As the organization makes the supply chain visible to all their partners, it adds values and responsibilities to every partner in the business.

- Virtual Integration: this helps every channel in the entire supply chain to use the real-time and same data for data visibility and for better decision making.

- Efficiency: Finding out the process gap and remedying them on a continuous improvement process is critical to compete with the market and take competitive advantage over others. This include engaging all the business partners to be part of this process and make a collective and decisive actions to deploy the right processes in the system.

\subsection{Implementation of Beacon Technology}

The product goes to manufacturer from the supplier and then it goes to retailers to market their product using this Beacon technology.

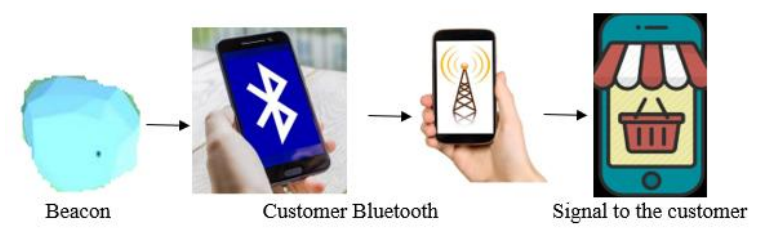

Fig:9 Implementation of the Beacon technology The figure 9 represents the beacon technology by the retailer.It is a small Bluetooth radio transmitter. It does looks like a lighthouse, it repeatedly transmits a single signal that other devices broadcasts a radio signal that is made up of a combination of letters and numbers transmitted on a regular interval of approximately 1/10th of a second. After when the product reaches the retailer store the Beacon was placed anywhere in the store. The beacons then connected to the customer Bluetooth enabled smart phone app. A signal is sent to the customer phone when the app is opened. Any type of the targeted information like product information, tracking the product place like can provide by the retailer to the customer. So hence by implementing this kind of the technologies the supply chain gets improved also the business can yield can severely increases.

\section{Results}

For the development of the business and the supply chain improvement the forward vertical integration method with 6-Sigma concept was implemented. Also, for the retailer and customer satisfaction the beacon technology was also to be implemented. The above implemented technique performance was evaluated by implementing the concept in an organization and check the yield profit should increase or not.

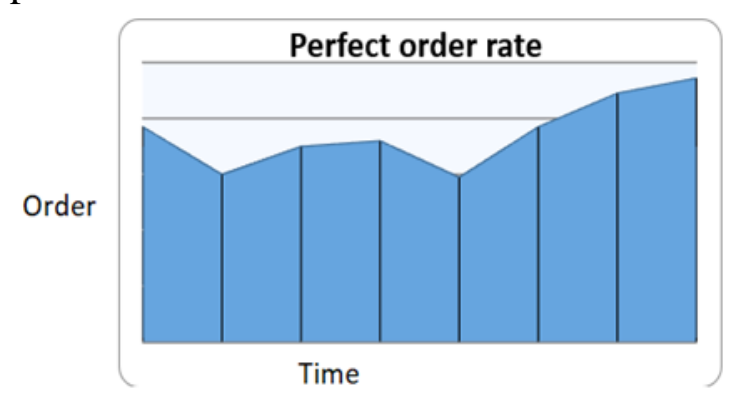

\section{Fig:10 Perfect order rate measurement}

The figure 10 in which we implement the forward vertical integration 6-Sigma technique so the training for all the workers are given depend upon that technique. So, after implementing that technique the perfect order was measured it is nothing but how much the order which can completed safely. After the implementation of the technique our goal also gets increases. So, there is no product return so supply chain cannot be disturbed.

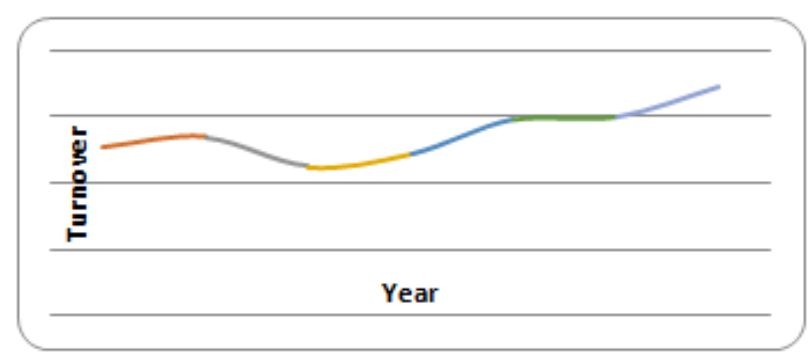

Fig:11 Inventory turnover

The figure 11 represents the process of inventory turnover. Here in which we can measure how much the amount of manufactured product to be sold out. The company has implemented the novel 
www.rspsciencehub.com

business improvement technique on 2019 so in that year turnover also be increased gradually.

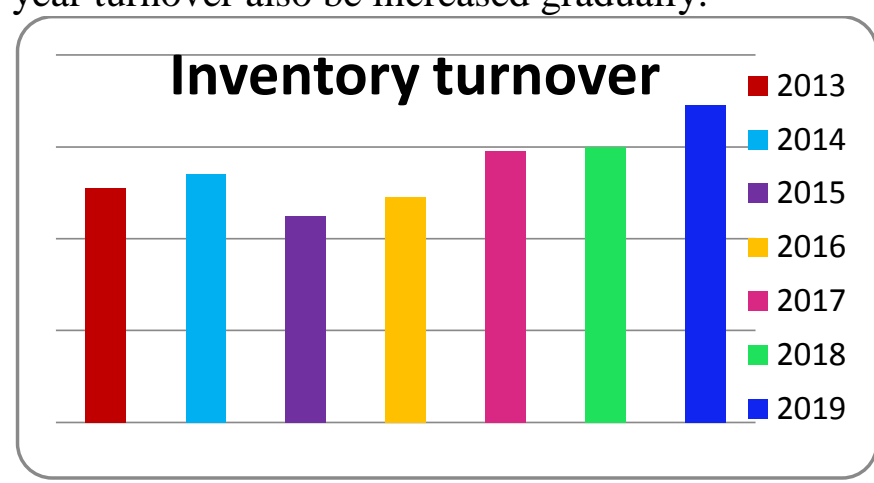

Fig:12 Inventory turnover representation

The figure 12 represents the bar chart representation of the inventory turnover year by year.

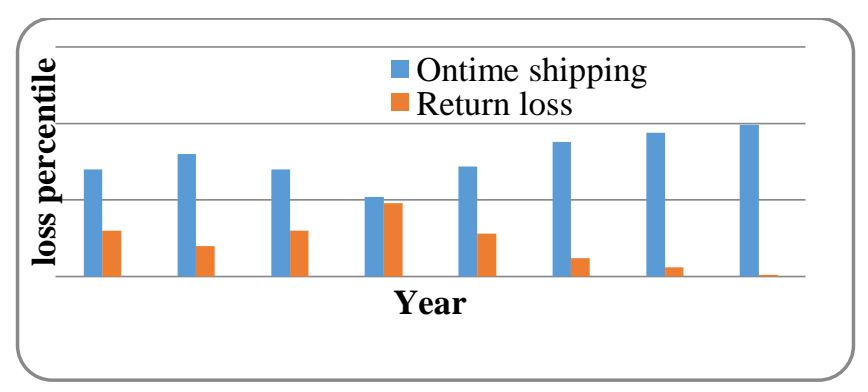

Fig:13 On time shipping Vs. Return loss

The figure 13 represents the comparison of the shipping time and the return loss by month wise. Here the shipping time can be gone our regularly i.e. shipping time increases product return also be high. Here from June 2019 after the implementation of the Forward vertical integration 6-Sigma technique on time shipping is high i.e. the shipping or delivery of the product can occur at a correct expected time so the return loss will get decreased.

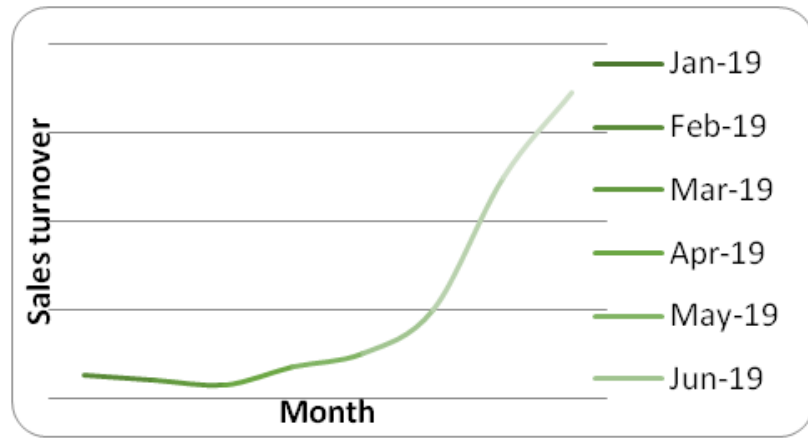

Fig:14 Months Vs. Sales Turnover
Volume 02 Issue 07 July 2020

The figure 14 represents the month Vs. sales turnover. After the implementation of the Forward vertical integration 6-Sigma technique month by month the manufactured product outgoing and the sales turn over will get increases gradually.

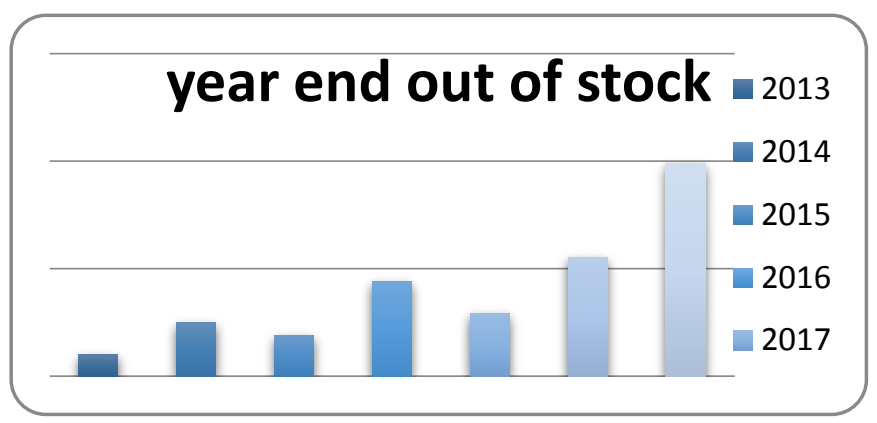

Fig:15 Year end out of stock

The figure 15 represents the year end out of stock. Here in which in the year of 2019 after the implementation of the Forward vertical integration 6-Sigma technique the product production also be high the quality of the product is also excellent so there is a null stock of the manufactured product in the year end.

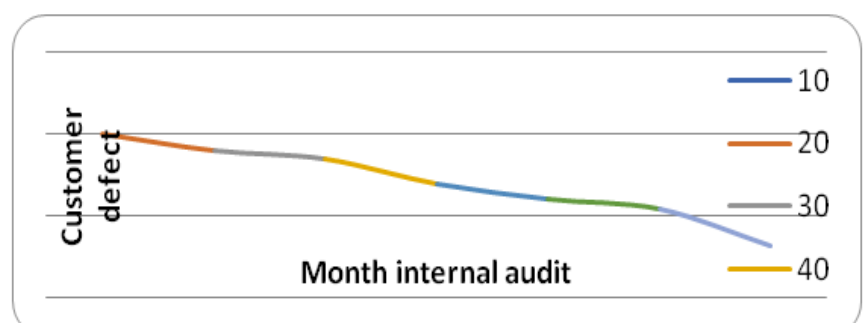

Fig:16 Month internal audit Vs. customer defect

The figure 16 represents the customer defects. Generally, customer defects occur due to the unqualified product they will return the product or else they do not oblige to pay for the product. This kind of situation decrease gradually after the implementation of the Forward vertical integration 6-Sigma technique

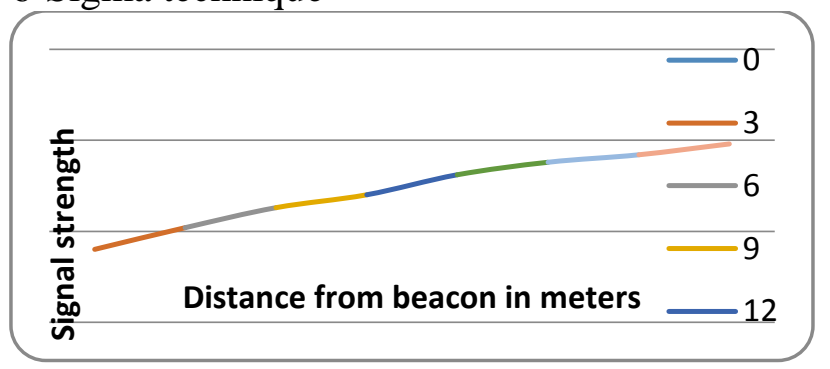

Fig:17 Measurement of the Beacon signal strength 
The figure 17 represents the implementation of the beacon technology for improving the business opportunities of the retailer. The signal strength of the beacon is high when the distance in meter is low.

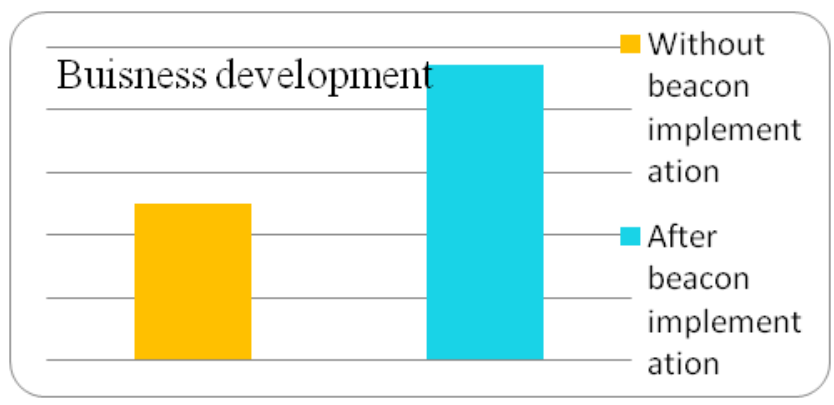

Fig:18 Business Development Chart

The figure 18 represents the overall business and supply chain improvement due to the implementation of the implementation of the Forward vertical integration 6-Sigma technique. The overall supply chain and business improvement is $94.4 \%$ in the year of 2019 .

\section{Conclusion}

It has been revealed based on this research that the effective implementation of the Forward Vertical Integration with the 6-Sigma technique has positioned / employed the workers very well and at the right positions for the excellent product / service. The organization has enjoyed the process of Supply Chain Performance Improvement and other inventory and financial benefits thru the FVI and 6-Sigma.Along with these FVI and 6-Sigma techniques, the implementation of Beacon technology had also offered tremendous advantages including cost benefits to the business, especially in the Warehouse Management space. This research can be further extended to other areas in the Supply Chain and can also be extended to a different type of Warehouse Management System implementations too.

\section{References}

[1]Chakra borty, T., Chauhan, S. S., \&Ouhimmou, M. (2018). Cost-sharing mechanism for product quality improvement in a supply chain under competition. International Journal of Production Economics. doi:10.1016/j.ijpe.2018.12.015

[2] Taleizadeh, A. A., Alizadeh-Basban, N., \&AkhavanNiaki, S. T. (2019). A closed-loop supply chain considering carbon reduction, quality improvement effort, and return policy under two remanufacturing scenarios. Journal of Cleaner Production. doi:10.1016/j.jclepro.2019.05.372

[3]. Aramyan, L.H., Lansink, A., Van Der Vorst, J., Van Kooten, O. (2007), "Performance Measurement in Agri-Food Supply Chains: A Case Study", Supply Chain Management: An International Journal, 12(4), pp. 304-315.

[4]. Ayers, J. B., (2001), "Handbook of Supply Chain Management", CRC Press, United States of America.

[5]. Batson, R. G., (2008), "A Survey of Best Practices in Automotive Supplier Development", International Journal of Automobile Technology Management, 8(2), pp. 129-144.

[6]. Beamon, B. (1999), "Measuring Supply Chain Performance", International Journal of Operations and Production Management, 19(3), pp. 275-292.

[7]. Benjamin, R., Wigand, R., (1995), Electronic Markets and Virtual Value Chains on the Information Superhighway", Sloan Management Review, 36(2), pp. 62-72.

[8].Chopra, S., Meindl, P. (2001), "Supply Chain Management: Strategy, Planning, and Operation", Prentice Hall, India.

[9]. Chopra, S., Meindl, P. (2004), "Supply Chain Management”, Prentice-Hall, 2, India.

[10]. Chopra, S., Meindl, P., Kalra, D.V. (2008), "Supply Chain Management: strategy, Planning and Operations" Prentice Hall, 2, India.

[11]. Chow, W.S., Madu, C.N., Kuei, C.H., Lu, M.H., Lin, C., Tseng, H., (2008), "Supply Chain Management in the US and Taiwan: An Empirical Study", The International Journal of Management Science, 36 (8), pp. $665-679$. 
[12]. Christopher, M. (1994), "Logistics and Supply Chain Management”, Piman Publishing, New York, NY.

[13]. Christopher, M., (1994), "Logistics and Supply Chain Management", Richard D. Irwin, Incorporation, Financial Times, New York, NY.

[14]. Christy, D., P., Grout, J., R. (1994), "Safeguarding Supply Chain Relationships", International Journal of Production Economics, 36, pp. 233- 242.

[15]. Cohen, M.A., Lee, H.L. (1989), "Resource Deployment Analysis of Global Manufacturing and Distribution Networks", Journal of Manufacturing and Operations Management, 2, pp. 81-104.

[16]. Cohen, M.A., Moon, S. (1990), "Impact of Production Scale Economies, Manufacturing Complexity and Transportation Costs on Supply Chain Facility Networks", Journal of Manufacturing and Operations Management, 3, pp. 269-292.

[17]. Cuthbertson, R., Piotrowicz, W. (2008), "Supply Chain Best Practices Identification and Categorisation of Measures and Benefits", International Journal of Productivity and Performance Management, 57(5), pp. 389-404.

[18]. Davis, T. (1993), "Effective Supply Chain Management", Sloan Management Review, 35, pp. 46-47.

[19]. De Toni, A., Tonchia, S., (2001) "Performance Measurement Systems: Models: Characteristics and Measures", International Journal of Operations \& Production Management, 21(1/2), pp. 46-70.

[20]. Davis, T., (1993), "Effective Supply Chain Management", Sloan Management Review, Summer, pp. 35-46. 